\title{
FACTORS AFFECTING IMPLEMENTATION OF PREFERENCE AND RESERVATION DIRECTIVE ON GOVERNMENT PROCUREMENT OPPORTUNITIES IN KENYA
}

\author{
${ }^{1}$ Awuor Arunga (iD \\ ${ }^{1}$ Department of Procurement, Jomo Kenyatta University of Agriculture and Technology \\ Corresponding author's e-mail: awuorarunga@gmail.com
}

How to cite this article: Arunga, A. (2021). Factors affecting implementation of preferences and reservation directive on government procurement opportunities in Kenya. Edith Cowan Journal of Procurement \& Supply Chain, 1(1), 1-9.

\section{ARTICLE INFO \\ Article history: \\ Received Date: $1^{\text {nd }}$ Nov 2020 \\ Revised Date: $4^{\text {th }}$ Dec 2020 \\ Accepted Date: $17^{\text {th }}$ Dec 2020}

\section{Keywords:}

Regulatory framework, ethical, compliance, preference, reservation directive

\section{A B S T R A C T}

Purpose: The purpose of the study was to determine factors affecting implementation of preference and reservation directive on government procurement opportunities in Kenya:a case of the central bank of Kenya.

Design/ Methodology/Approach: The investigation utilized stratified arbitrary inspecting, the adolescent, ladies and people with handicaps being the strata of particular elements prequalified with the Central Bank of Kenya in its mind office in Nairobi and the three branches (Mombasa, Kisumu and Eldoret). From that point straightforward arbitrary testing was utilized to choose 310 respondents from the strata whom were issued with surveys. Information was gathered utilizing self-regulated polls. The information gathered was broke down by utilization of illustrative and inferential measurements. Numerous relapse models were utilized to demonstrate the connection between the reliant variable and the free factors.

Findings: $R$ square value of 0.768 means that $76.8 \%$ of the corresponding variation in implementation of the $30 \%$ preference and reservation directive on government procurement in Kenya can be explained or predicted by (regulatory framework and requirements, procurement opportunity awareness and sensitization, capacity of disadvantaged groups, ethical and compliance issues) which indicated that the model fitted the study.

Contribution to policy and practice: The discoveries of the investigation demonstrated that administrative system and prerequisites, obtainment opportunity mindfulness and sharpening, limit of distraught gatherings, moral and consistence issues have a positive association with execution of the $30 \%$ inclination and reservation order on government acquirement openings in Kenya.

Originality/Value: The study extends the literature on open organizations and recommends that they should grasp administrative structure and prerequisites, acquisition opportunity mindfulness and refinement, limit of impeded gatherings, moral and consistence issues in order to improve usage of the $30 \%$ inclination and reservation. 


\section{BACKGROUND}

In the ongoing past, most governments have concocted a technique for guaranteeing that the less burdened, nearby sellers and little and medium endeavors inside the economy have an edge while contending in a similar pool with vast and built up organizations (Liebrandt and Mlastsheni, 2014). The securing elements in that occurrence may choose to make inclination to an impeded gathering amid an assessment by expanding the offer of the non-favored organizations most likely by a consistent $10 \%$. The inclination to the burdened gatherings, for example, the young, debilitated and the ladies is intended to protect them from segregation. It is up and coming that the realization of the inclination gather is intended to guarantee that these gatherings participate in the exercises of a formal economy (Mahmood, 2010).

Most developed nations spend about $20 \%$ of gross domestic product (GDP) on public procurement while developing nations spend up to 50\% (Carter, 2010). For instance, in the United States, federal public procurement during 2009 accounted for over $\$ 534$ and over 13\% of the total federal budget. Instructions to the United States treasury are to ease the assessment of funds to start-ups at affordable interest rates and extended payback period (Christine, 2006).

For the longest time, the Africa continent has been marred by persistent corruption and lack of proper public procurement machineries (Badenhorst, 2012). It is imperative to note that an effective public procurement system that offers high level of transparency, accountability and value for money is critical for poverty reduction in developing countries. It is also the pillar for promotion of good governance and sustainable development in any economy.

According to the World Bank (2008) a public procurement system is said to be well functioning if it achieves the objectives of transparency, economy, fairness, competition and accountability. In pursuit of this, the Kenyan government enacted the Public procurement and Disposal Act 2005 which become operational in 2007 and was followed by other regulations. As described by Public Procurement Oversight Authority, the Public Procurement System in Kenya has evolved from a crude system with no regulations to an orderly legally regulated procurement system (Wanyama, 2010).

\section{Research Problem}

In Kenya, special groups constitute over $85 \%$ of the entire population yet they contribute to less than $10 \%$ of public procurement involvement thus hampering economic growth and achievement of vision 2030 (Transparency International, 2010). Current statistics show that the special groups also constitute the highest unemployment rate of $67 \%$ (KNBS, 2013). In the financial year 2013/2014, 200 billion (30\% of government procurement) was allocated for the youth. However, analysis of the financial year 2013/2014 expenditures by the Women Enterprise Fund on special group access reveal that only Ksh. 2.8B against an allocation of Kshs.200B was expended showing that only $1.4 \%$ of the allocation was actually spent on Access to Government Procurement Opportunities (AGPO) instead of the mandatory $30 \%$ (UNESCO, 2014).

Many of the problems cited by the special groups have included capacity building, lack of access to credit, inadequate skills, poor information and inhibitive legal regulatory framework (PPOA, 2007). The implementation outcome of the $30 \%$ government procurement preference for youth, women and persons with disabilities (access to government procurement opportunities) 
is anticipated to make a significant contribution to GDP of not less than $15 \%$ per annum (GoK, 2013). Consequently, the government has established institutions that are training the youth on various opportunities available in the market. They have also created institutions that provide financial help (YEDP and UWEZO funds) and relaxed registration requirement to make it easier for this group to get involved (KPMG, 2008).

Despite of all this efforts, it's unclear to what extent these groups are actually participating in public procurement. Several studies have been done; Ng'ang'a (2011) interrogated the factors influencing public bidding by youth entrepreneurs, while Gitari and Kabare (2014) assessed factors affecting access to procurement opportunities in public secondary schools by small and medium enterprises in Kenya. These studies barely focused on access to government procurement opportunities. Ogachi (2011) examined the effectiveness of public procurement audits for constituency development funds in Kenya. However, they did not address the challenges facing the implementation of 30\% preference and reservation directive in Kenya.

While much research has focused on the problems facing performance of special groups companies under the $30 \%$ preference and reservation directive on government procurement projects in Kenya, not much research has been done to study factors affecting implementation of the $30 \%$ preference and reservation directive on government procurement opportunities in Kenya and also considering the pivotal role that the youth play in development, their participation in public procurement is paramount. It is against this back drop that this study seeks to assess the factors affecting implementation of the 30\% preference and reservation directive on government procurement opportunities in Kenya, with particular focus on the Central Bank of Kenya.

\section{Study Objectives}

i. To assess the effect of regulatory framework and requirements on implementation of the 30\% preference and reservation directive on government procurement in Kenya.

ii. To establish the effect of procurement opportunity awareness and sensitization on implementation of the $30 \%$ preference and reservation directive on government procurement in Kenya.

iii. To determine the effect of capacity of disadvantaged groups on implementation of the $30 \%$ preference and reservation directive on government procurement in Kenya.

iv. To evaluate the effect of ethical and compliance issues on implementation of the $30 \%$ preference and reservation directive on government procurement in Kenya.

\section{LITERATURE}

\section{Information Technology Integration and Efficiency in Tendering Process}

According to Alex (2013), IT is transforming the way the business is conducted. Computers prepare invoices, issue checks, track inventory movements and store staff and payroll data. Personal computers are changing models of office work, and the spread of information technology is affecting the efficiency and competitiveness of companies, the structure of the workforce and the general growth of economic production.

\section{Regulatory Framework and Efficiency in Tendering Process}

Organizations that face high pressure in terms of regulatory compliance tend to better implement the policies and regulations put in place (Zhu \& Sarkis, 2010). However, government regulations are not very significant in sustainable procurement process (Carter \& Jennings, 
2014). Therefore, coercive isomorphism enables parastatals in adopting procurement regulations for efficient procurement process and to support performance of an organization. In a way it urges parastatals to make their regulations that intertwine with government's policies without necessarily relying on government's regulations (Arjaan \& Van, 2010).

\section{Procurement Opportunity Awareness and Sensitization}

According to Lysons et al (2013), awareness is defined as knowing something; knowing that something exist and is important; being interested in something. Market opportunity awareness is a combination of commercial awareness and situation awareness which is defined as perception of environmental elements with respect to time and space, comprehension of their meaning and projection of their status after some variable have changed (Mahmood, 2010).

\section{Capacity of Disadvantaged Groups}

Obanda (2011) analyzed the strategic and management interventions that can enable youth, women and persons with disabilities in Uganda obtain public procurement contracts to maximize sustainability in the context of inclusive growth. The study established that the challenge youth, women and persons with disabilities face in accessing public contracts also depends on how they themselves increase their capacity to fulfill government contracts. The study recommended among other things that governments in developing economies should play a significant role in eliminating the supply side constraints.

\section{Institutional Theory}

Institutional theory is a widely used theory in social studies. Kraft's public policy summarizes the theory as a policy-making that emphasizes the formal and legal aspect of government structures (Zheng, 2007). It considers processes by which structures, including schemes and rules become established by authoritative figures as guidelines for social behavior.

Wood (2012) portends that it explains how the elements are created, diffused, adopted, and adapted over space and time; and how they fall into decline and disuse. Institutions are transmitted by various types of carriers, including symbolic systems, relational systems, routines, and artifacts. Institutions operate at different levels of jurisdiction, from the world system to localized interpersonal relationships.

In this context, access to government procurement opportunities, is entrenched and implemented within the purview of the law, to provide tangible support to the special groups who form above $60 \%$ of the population yet facing wide unemployment. However, as this study has established, the rate of success of this institutional agenda is not giving an impressive output. As Puddephatt and Kaspar (2012) explain, this theory assisted the researcher to understand how the specific objective of determining the influence of regulatory framework and requirements on access to government procurement opportunities.

research that involves data collection from members of a sample for the purpose of estimating one or more population parameters. Survey design is appropriate for this study as it provides description and accounts of business events and objects of research in their natural setting and thus portrays the actual picture. The study targeted Small and Medium Enterprises (SME'S) in Elgeyo/ Marakwet County totaling 2000. The study employed Nassiuma (2000) sample size determination formula to arrive at 95 SMEs. The study adopted stratified sampling and sampling technique where the County was sub divided into 4 sub counties namely; Marakwet East, Marakwet West, Keiyo North and Keiyo South. The simple random Sampling technique will be used to pick respondents from each sub county. Each sub county is expected to generate 22 respondents which will total to 88 and 7 from county Government who will be used as a control 
totaling to 95. The study employed correlation and Ordinal Least Squares (OLS) regression to model the relationship between financial perspective and financial performance of SMEs.

\section{MATERIALS AND METHODS}

The investigation utilized stratified arbitrary inspecting, the adolescent, ladies and people with handicaps being the strata of particular elements prequalified with the Central Bank of Kenya in its mind office in Nairobi and the three branches (Mombasa, Kisumu and Eldoret). From that point straightforward arbitrary testing was utilized to choose 310 respondents from the strata whom were issued with surveys. Information was gathered utilizing self-regulated polls. The information gathered was broke down by utilization of illustrative and inferential measurements. Correlation and regression models were utilized to demonstrate the connection between the reliant variable and the free factors.

\section{RESULTS}

\section{Correlation Analysis}

Correlation analysis was used to determine both the significance and degree of association of the variables and also predict the level of variation in the dependent variable caused by the independent variables. The correlation summary shown in Table 1.

Table 1 Correlation Results

\begin{tabular}{|c|c|c|c|c|c|}
\hline Variables & 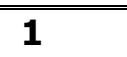 & 2 & 3 & 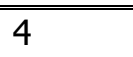 & 5 \\
\hline 1.Regulatory Framework and Requirements & 1 & & & & \\
\hline $\begin{array}{l}\text { 2.Procurement Opportunity Awareness and } \\
\text { Sensitization }\end{array}$ & $.531 * *$ & 1 & & & \\
\hline 3. Capacity of Disadvantaged Groups & $.569 * *$ & $.385^{* *}$ & 1 & & \\
\hline 4.Ethical and Compliance Issues & $.547 * *$ & $.782 * *$ & $.446 * *$ & 1 & \\
\hline $\begin{array}{l}\text { 5. Implementation of the } 30 \% \text { Preference and } \\
\text { Reservation Directive }\end{array}$ & $.815^{* *}$ & $.605^{* *}$ & $.663 * *$ & $.656 * *$ & 1 \\
\hline
\end{tabular}

** Correlation is significant at the 0.05 level (2-tailed).

Table 1 indicates that the associations between each of the independent variables and the dependent variable were all significant at the $95 \%$ confidence level. The correlation analysis to determine the relationship between factors affecting implementation of the $30 \%$ preference and reservation directive on government procurement in Kenya, Pearson correlation coefficient computed and tested at 5\% significance level.

The results indicate that there is a positive relationship $(r=0.815)$ between regulatory framework and requirements and implementation of the $30 \%$ preference and reservation directive on government procurement in Kenya. In addition, the researcher found the relationship to be statistically significant at $5 \%$ level $(p=0.000,<0.05)$.

The correlation analysis to determine the relationship between procurement opportunity awareness and sensitization and implementation of the $30 \%$ preference and reservation directive on government procurement in Kenya, Pearson correlation coefficient computed and tested at $5 \%$ significance level. The results indicate that there is a positive relationship $(r=0.605)$ between procurement opportunity awareness and sensitization and implementation of the $30 \%$ preference and reservation directive on government procurement in Kenya. In 
addition, the researcher found the relationship to be statistically significant at $5 \%$ level $(p=0.000,<0.05)$.

The correlation analysis to determine the relationship between of capacity of disadvantaged groups on and implementation of the $30 \%$ preference and reservation directive on government procurement in Kenya, Pearson correlation coefficient computed and tested at $5 \%$ significance level. The results indicate that there is a positive relationship $(r=0.663)$ between of capacity of disadvantaged groups and implementation of the $30 \%$ preference and reservation directive on government procurement in Kenya. In addition, the researcher found the relationship to be statistically significant at $5 \%$ level $(p=0.000,<0.05)$.

The correlation analysis to determine the relationship between ethical and compliance issues and implementation of the $30 \%$ preference and reservation directive on government procurement in Kenya Pearson correlation coefficient computed and tested at $5 \%$ significance level. The results indicate that there is a positive relationship $(r=0.656)$ between ethical and compliance issues and implementation of the $30 \%$ preference and reservation directive on government procurement in Kenya. In addition, the researcher found the relationship to be statistically significant at $5 \%$ level $(p=0.000,<0.05)$. Hence, it is evident that all the independent variables could explain the changes in implementation of the $30 \%$ preference and reservation directive on government procurement in Kenya, on the basis of the correlation analysis.

\section{Regression Analysis}

Multivariate regression analysis was used to determine the significance of the relationship between the dependent variable and all the independent variables pooled together. Regression analysis was conducted to find the proportion in the dependent variable (implementation of the $30 \%$ preference and reservation directive on government procurement in Kenya) which can be predicted from the independent variables (regulatory framework and requirements, procurement opportunity awareness and sensitization, capacity of disadvantaged groups, ethical and compliance issues). Table 2 shows the model summary.

Table 2 Model Summary

\begin{tabular}{lllll}
\hline Model & $\mathbf{R}$ & R Square & Adjusted R Square & Std. Error of the Estimate \\
\hline 1 & $.876^{\mathrm{a}}$ & .768 & .762 & .112 \\
\hline
\end{tabular}

a) Predictors: (Constant), Regulatory Framework and Requirements, Procurement Opportunity Awareness and Sensitization, Capacity of Disadvantaged Groups, Ethical and Compliance Issues

b) Dependent Variable: Implementation of the $30 \%$ Preference and Reservation Directive

Table 2 presents the regression coefficient of independent variables against dependent variable. The results of regression analysis revealed there is a significant positive relationship between dependent variable and the independent variables. The independent variables reported $R$ value of 0.876 indicating that there is perfect relationship between dependent variable and independent variables. $\mathrm{R}$ square value of 0.768 means that $76.8 \%$ of the corresponding variation in implementation of the $30 \%$ preference and reservation directive on government procurement in Kenya can be explained or predicted by (regulatory framework and requirements, procurement opportunity awareness and sensitization, capacity of disadvantaged groups, ethical and compliance issues) which indicated that the model fitted the study data. Table 3 shows the analysis of variance results. 
Arunga (2020)

Page 7 of 9 
Table 3 ANOVA Results

\begin{tabular}{|c|c|c|c|c|c|c|}
\hline Model & & $\begin{array}{l}\text { Sum } \\
\text { Squares }\end{array}$ & of $\mathbf{d f}$ & Mean Square & $\mathbf{F}$ & Sig. \\
\hline \multirow[t]{3}{*}{1} & Regression & 7.21 & 4 & 1.803 & 143.696 & $.000^{b}$ \\
\hline & Residual & 2.183 & 174 & 0.013 & & \\
\hline & Total & 9.393 & 178 & & & \\
\hline
\end{tabular}

a) Predictors: (Constant), Regulatory Framework and Requirements, Procurement Opportunity Awareness and Sensitization, Capacity of Disadvantaged Groups, Ethical and Compliance Issues

b) Dependent Variable: Implementation of the $30 \%$ Preference and Reservation Directive

Table 3 presents the Analysis of Variance results which indicates that independent variables are significant predictor of implementation of the $30 \%$ preference and reservation directive ( $F$ statistics $=143.696, p=0.000<0.05)$. Table 4 shows the regression results.

Table 4 Regression Results

\begin{tabular}{|c|c|c|c|c|c|c|}
\hline \multirow{2}{*}{\multicolumn{2}{|c|}{ Model }} & \multicolumn{2}{|c|}{$\begin{array}{l}\text { Unstandardized } \\
\text { Coefficients }\end{array}$} & \multirow{2}{*}{$\begin{array}{l}\text { Standardized } \\
\text { Coefficients } \\
\text { Beta } \\
\end{array}$} & \multirow[t]{2}{*}{$\bar{t}$} & \multirow[t]{2}{*}{ Sig. } \\
\hline & & B & Std. Error & & & \\
\hline \multirow[t]{5}{*}{1} & (Constant) & 0.713 & 0.216 & & 3.298 & 0.001 \\
\hline & $\begin{array}{l}\text { Regulatory Framework } \\
\text { and Requirements }\end{array}$ & 0.617 & 0.058 & 0.526 & 10.66 & 0.000 \\
\hline & $\begin{array}{l}\text { Ethical and Compliance } \\
\text { Issues }\end{array}$ & 0.085 & 0.026 & 0.203 & 3.301 & 0.001 \\
\hline & $\begin{array}{l}\text { Capacity of } \\
\text { Disadvantaged Groups }\end{array}$ & 0.062 & 0.012 & 0.245 & 5.167 & 0.000 \\
\hline & $\begin{array}{l}\text { Procurement } \\
\text { Opportunity Awareness } \\
\text { and Sensitization }\end{array}$ & 0.038 & 0.032 & 0.072 & 1.208 & 0.020 \\
\hline
\end{tabular}

a) Predictors: (Constant), Regulatory Framework and Requirements, Procurement Opportunity Awareness and Sensitization, Capacity of Disadvantaged Groups, Ethical and Compliance Issues

b) Dependent Variable: Implementation of the $30 \%$ Preference and Reservation Directive

The research used a multiple regression model

$$
Y=\beta_{0}+\beta_{1} X_{1}+\beta_{2} X_{2}+\beta_{3} X_{3}+\beta_{4} X_{4}+\varepsilon
$$

Where $\mathbf{Y}=$ Implementation of the $30 \%$ preference and reservation directive on government procurement

$\mathbf{B}_{\mathbf{0}}=$ Constant

$\mathbf{X}_{\mathbf{1}}=$ Regulatory Framework and Requirements

$\mathbf{X}_{\mathbf{2}}=$ Procurement Opportunity Awareness and Sensitization

$\mathbf{X}_{\mathbf{3}}=$ Capacity of Disadvantaged Groups

$\mathbf{X}_{\mathbf{4}}=$, Ethical and Compliance Issues

$\boldsymbol{\varepsilon}=$ Error Term At 95\% Confidence Level

The regression equation will be;

$$
Y=0.713+0.617 X_{1}+0.085 X_{2}+0.062 X_{3}+0.038 X_{4}
$$


The regression equation above has established that taking all factors into account (regulatory framework and requirements, procurement opportunity awareness and sensitization, capacity of disadvantaged groups, ethical and compliance issues) constant at zero, implementation of the $30 \%$ preference and reservation directive on government procurement in Kenya will be an index of 0.713 . The findings presented also shows that taking all other independent variables at zero, a unit increase in regulatory framework and requirements will lead to a 0.617 increase in implementation of the $30 \%$ preference and reservation directive on government procurement in Kenya. The P-value was 0.000 which is less 0.05 and thus the relationship was significant.

The study found that ethical and compliance issues will lead to a 0.085 decrease in the implementation of the $30 \%$ preference and reservation directive on government procurement in Kenya. The P-value was 0.001 and hence the relationship was significant since the $p$-value was lower than 0.05 .

In addition, the study found that a unit increase in capacity of disadvantaged groups will lead to a 0.062 increase in the implementation of the $30 \%$ preference and reservation directive on implementation of the $30 \%$ preference and reservation directive on government procurement in Kenya. The P-value was 0.000 and thus the relationship was significant.

The study also found that a unit increase in procurement opportunity awareness and sensitization will lead to a 0.038 increase in implementation of the $30 \%$ preference and reservation directive on government procurement in Kenya. The P-value was 0.02 and thus the relationship was significant.

The findings of the study show that, regulatory framework and requirements contributed most to the implementation of the $30 \%$ preference and reservation directive on government procurement in Kenya.

\section{CONCLUSION}

The study sought to examine the factors affecting implementation of the $30 \%$ preference and reservation directive on government procurement opportunities in Kenya: a case of the Central Bank of Kenya. The study targeted preferential entities prequalified by the Central Bank of Kenya. A total of 179 preferential entities participated

Based on the study findings, the study concludes that implementation of the $30 \%$ preference and reservation directive on government procurement opportunities can be improved by regulatory framework and requirements, procurement opportunity awareness and sensitization, capacity of disadvantaged groups, ethical and compliance issues.

\section{Areas for Further Research and recommendations}

The study is a milestone for further research in the field of factors affecting implementation of the $30 \%$ preference and reservation directive on government procurement opportunities in Kenya. The findings demonstrated the important factors affecting implementation of the $30 \%$ preference and reservation directive on government procurement opportunities to include; regulatory framework and requirements, procurement opportunity awareness and sensitization, capacity of disadvantaged groups, ethical and compliance issues.

The current study obtained an R2 of $76.8 \%$ and should therefore be expanded further in future in order to include other factors affecting implementation of the $30 \%$ preference and reservation directive on government procurement opportunities that may as well have a positive significance to affecting implementation of the $30 \%$ preference and reservation directive on government procurement opportunities. 


\section{REFERENCES}

Ibuathu, C. N., \& Kubaison, S. T. (2013). Realizing equal opportunities among youth groups in accessing government financial credit facilities. International Journal of Social Sciences and Entrepreneurship, 1 (7), 699-712.

ILO (2015). "Youth Pathways to decent work".Report IX Promoting Youth Employment tracking the challenge, ILO, 103rd Session, in Geneva

International Finance Corporation (2011). SME finance policy guide. G-20 finance policy guide. Washington DC: World Bank.

International Trade Centre (2008). Governance, Management, and Accountability in Secondary Education in Sub-Saharan Africa, working paper No. 127, New York: World Bank.

Jackson, S.L. (2009). Research Methods and Statistics: A Critical Thinking Approach 3rd edition. Belmont, CA: Wadsworth.

Kasomo, D. (2007). Research Methods in Humanities and Education, Eldoret; Zapf Chancery

Kenya National Bureau of Statistics (2013). Unemployment in Kenya: A situation analysis.

Kingori, N. (2012). Factors Affecting Procurement Manual Adoption by Secondary Schools in Kenya, Msc research project Jomo Kenyatta University of Science and Technology

Kingori, N. (2012). Factors Affecting Procurement Manual Adoption by Secondary Schools in Kenya, Msc research project Jomo Kenyatta University of Science and Technology

Kipchilat, G.T. (2009). "An Evaluation of the Impact of the Public Procurement Regulations on Procurement in Kenyan Public Universities." Unpublished MBA Project Egerton University, Nakuru, Kenya

Kitindi, S. (2012). Limuru District Development Plan. Nairobi: Ascent Limited.

Kothari, C.R. (2008). Research Methodology; Methods \& Techniques (2 ${ }^{\text {nd }}$ ed). New Delhi; New Age International Press Limited

KPMG (2008). Governance Survey. Nairobi: KPMG.

Liebrandt, M. \& Mlastsheni, C. (2014). Youth in South-Saharan Labour Markets, Paper presented at African Development and Poverty Reduction: The Macro-Micro Linkage Forum, Somerset West, South Africa.

Linarelli, J. \& Wallace, D. (2010). Regulating Public Procurement: National and International Perspectives. Kluwer Law International

Lysons, K., \& Farrington, B. (2008). Purchasing and Supply chain Management, (7th Ed) London: Prentice Hall.

Lysons, K., \& Gullingham, M. (2013). Purchasing and Supply Chain Management, (6th Ed). London: Pearsons Hall.

Mahmood, S. A. (2010). Public Procurement and Corruption in Bangladesh. Confronting the Challenges and Opportunities. Journal of Public Administration and Policy Research, 2(6), 103-111.

Manasseh, P.N. (2007). A text Book of Principles of Auditing. Nairobi: McMore Accounting Books. 